\title{
Challenges in Resource Rich Communities: Finding the Path to Redevelopment
}

\section{Mil Duncan}

\section{The Carsey Institute}

June 2, 2010 


\section{The Carsey Institute Programs}

Vulnerable Children and Families

- Child Poverty

- Working Family Policy

- Childhood Obesity

- Rural Youth
Sustainable Development

- Community Development Finance and Social Enterprise

- Community and Environment: change in resource dependent areas
Evaluation and Demography Resources

- Demographic analysis

- New evaluation center

- Workshops on methodology for faculty 


\section{This morning I will}

- Describe rural America as a context for thinking about redevelopment in northern forest communities; and

- Consider the role played by civic culture and civic institutions in development and change. 


\section{0 million people live in small town}

\section{and rural communities}

- $17 \%$ of the U.S. population on $80 \%$ of the land

- Slow, modest growth, though trends vary by type of community

- Over 7 million are poor in rural America
Figure 1. PopulationTrends in Metropolitan and Nonmetropolitan Areas 1920-2004

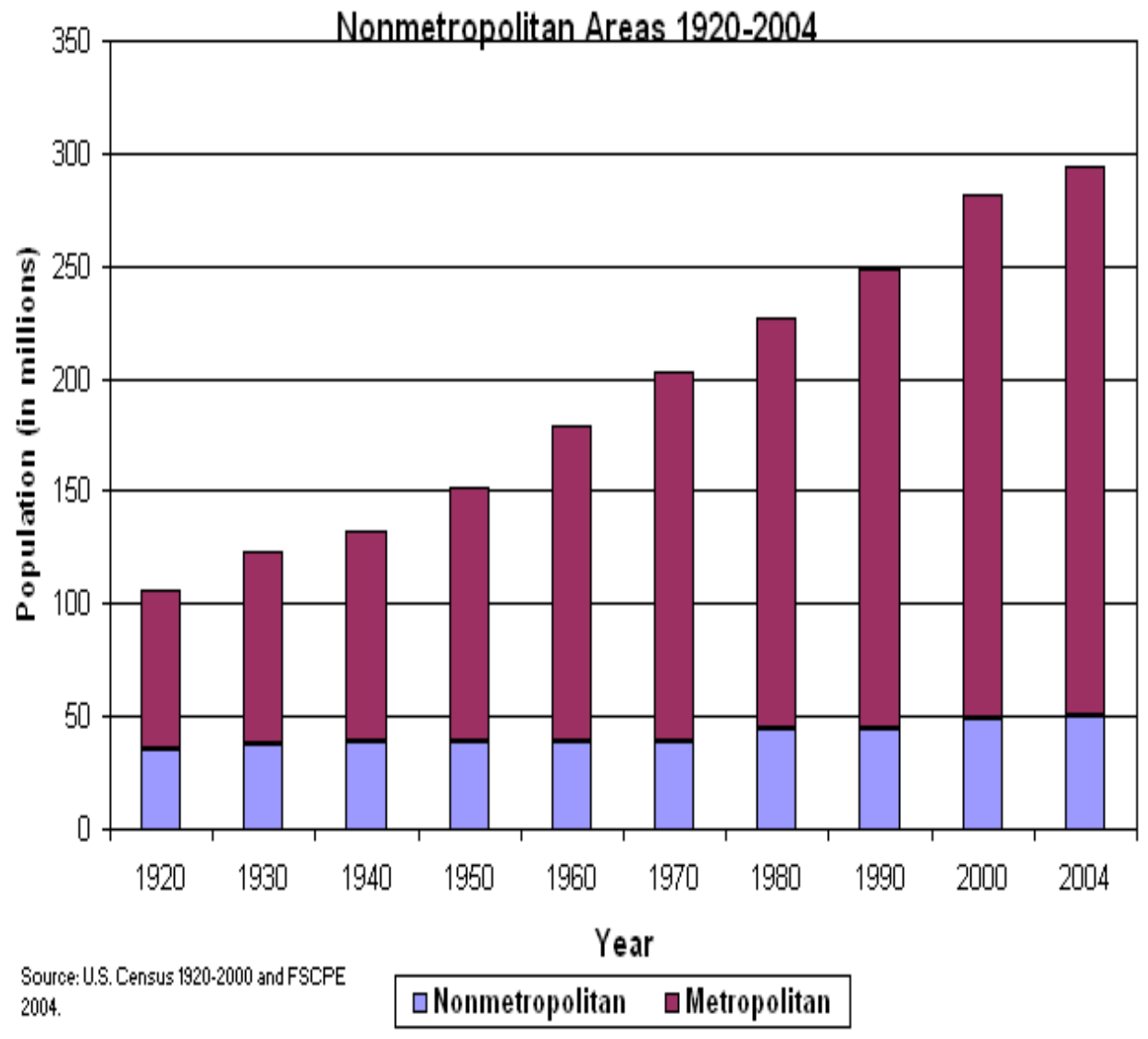




\section{Big challenges in rural America - even before the downturn really hit}

- Economic challenges Loss of blue collar jobs, decades of no investment in poor areas

- Demographic changes Aging, outmigration of young, areas where natural decrease is the pattern, a growing immigrant population

- Environmental pressures Environmental degradation, stress on natural resources, climate change; potential: in local food \& energy 


\section{Demographic shifts: the young have always left}

Recently, youth

outmigration is declining overall... $80 \%$ of youth in a recent Penn study left . Older groups are coming into rural

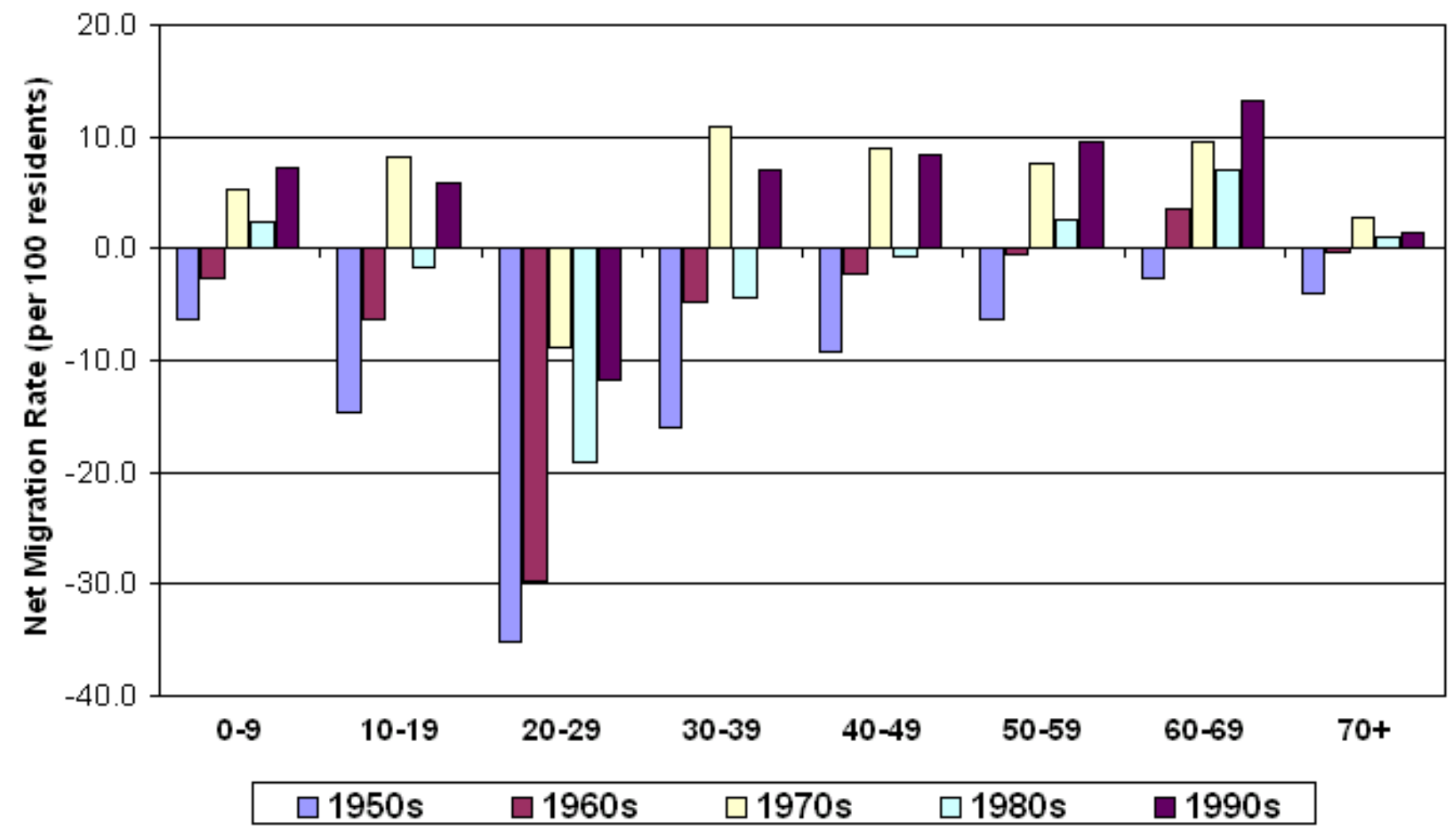
communities 


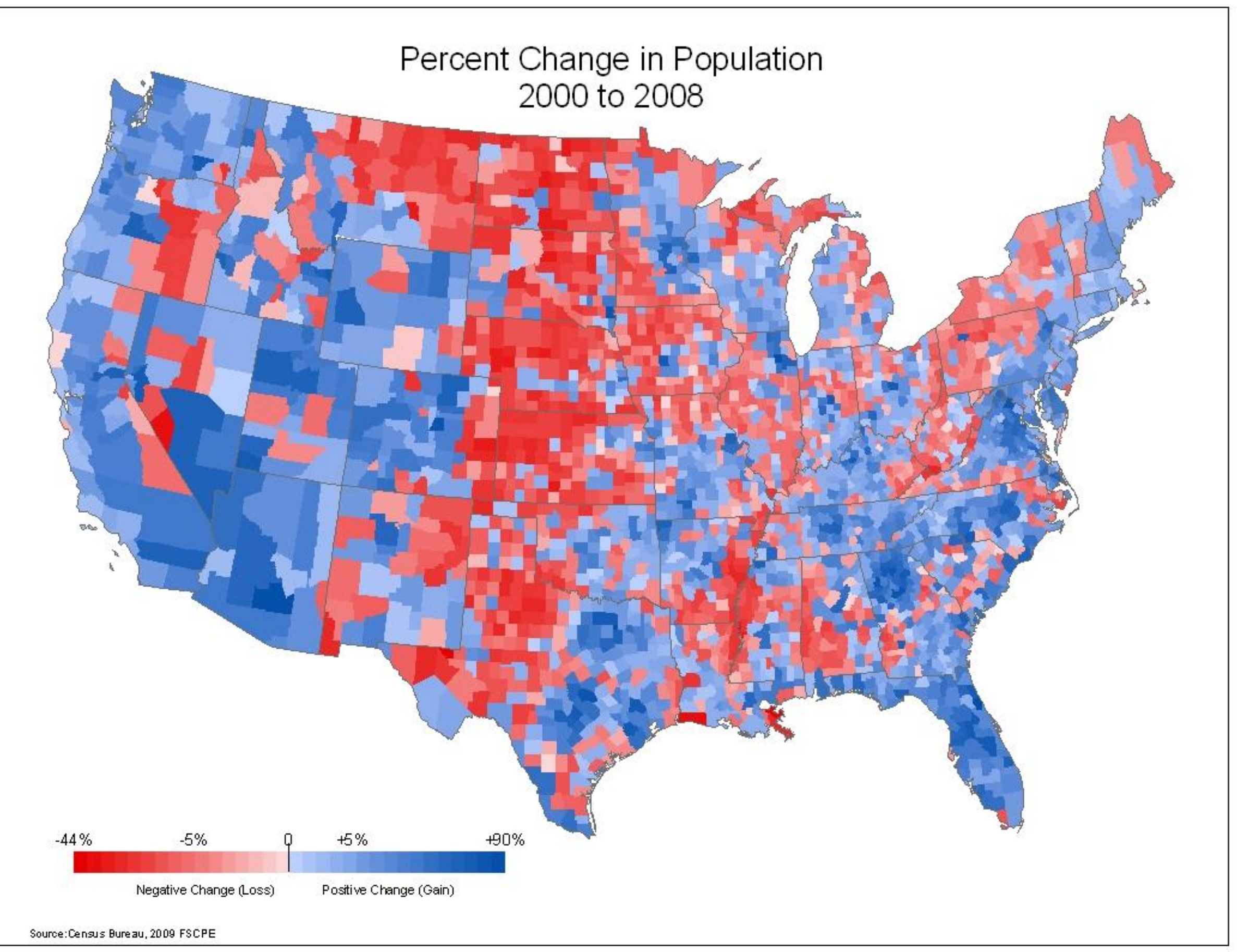


Distribution of Minority and Non-Hispanic White Population under Age 20, 2008

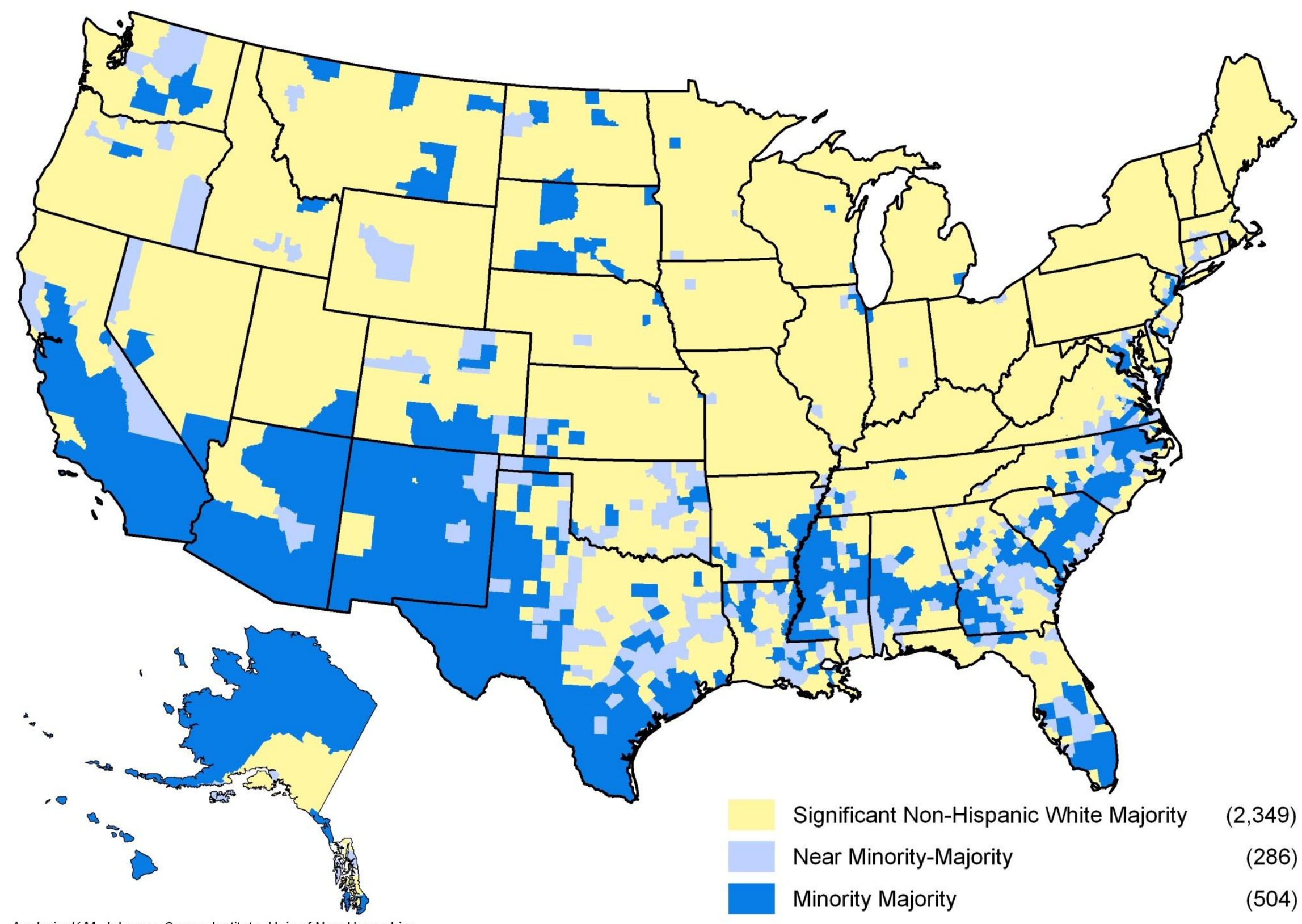




\section{Carsey's Survey on Community and Environment in Rural America}

Nonmetropolitan and metropolitan counties, 2003

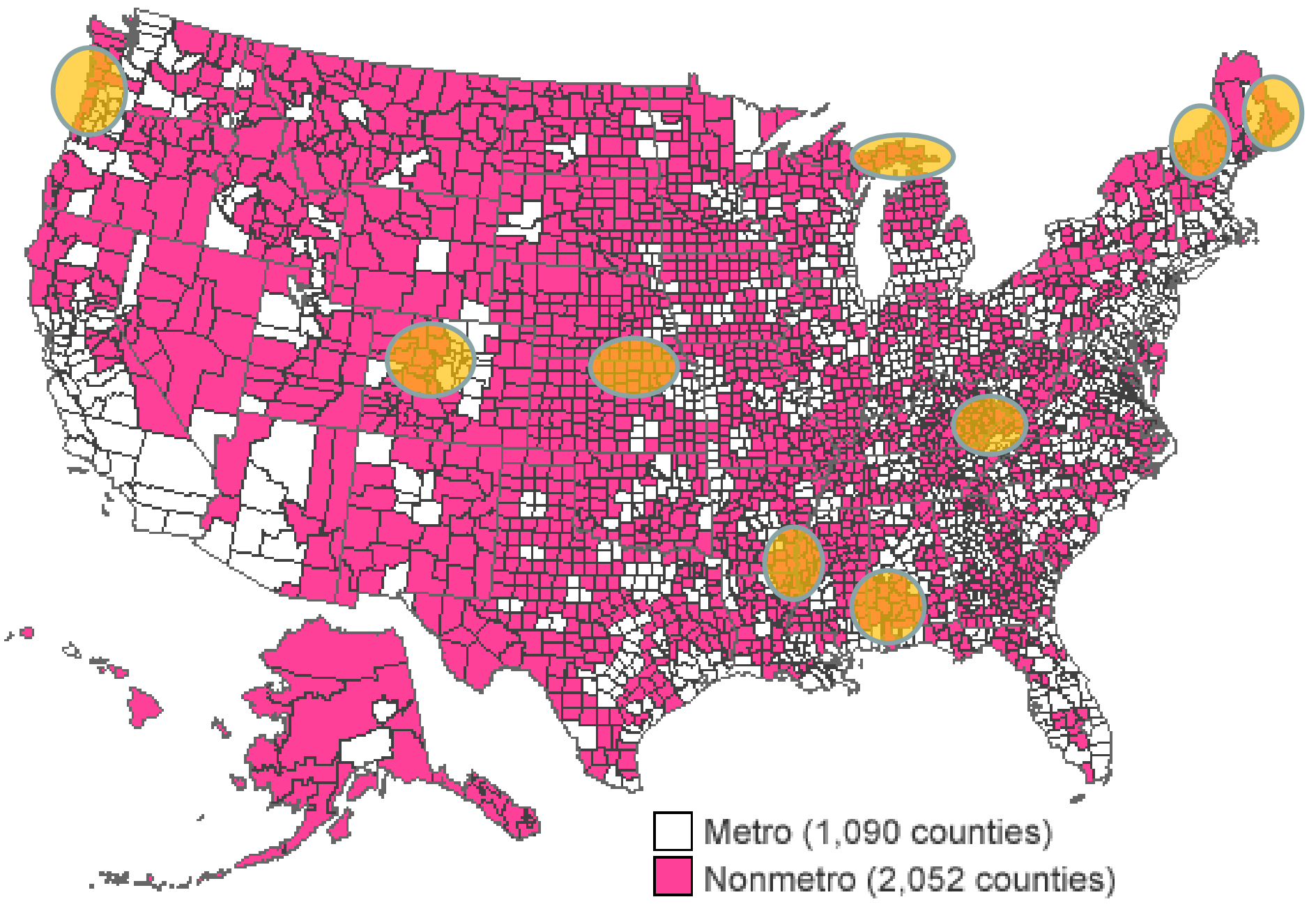

Source: Prepared by ERS using data from the Census Bureau. 


\section{The Community \& Environment in Rural America Survey}

- Telephone interviews

- 10,000 residents in 9 regions

- CO Rockies

- Great Plains

- Central Appalachia

- MS Delta

- AL Black Belt

- Northern Forest

- Pacific NW

- UP Michigan

- Downeast ME
- Roughly 100 questions

- Personal background and demographics

- Migration history and plans

- Economic/labor market experiences

- Views on community issues

- Findings presented in Place Matters: Challenges and Opportunities in Four Rural Americas 


\section{The "Four Rurals"}

\section{Amenity}

- Newcomers

- Growth

- Affluence

- Service economy

- Professionals

- Tourism

- Tied to natural beauty
Decline

- Traditional, resourcebased industry

- Low poverty

- High employment

- High civic engagement

- Importance of family ties

- Outmigration 


\section{The "Four Rurals"}

Amenity-Decline

- Decline of traditional industries

- Context of natural beauty

- Shifting relationship between communities and environment

- Relatively low poverty

- Strong civic culture

- Ties to family and natural beauty
Chronic Poverty

- High poverty

- Low education

- Low employment

- Weak civic culture

- Low civic engagement

- Often coupled with decline in traditional industries 


\begin{tabular}{|c|c|c|c|c|c|}
\hline REGION/TYPE & $\begin{array}{c}\text { POPN \% } \\
\text { CHANGE } \\
1990-2005\end{array}$ & $\begin{array}{c}\text { \% CHANGE } \\
\text { IN POPN } \\
\text { AGE 25-34 } \\
1990-2005\end{array}$ & $\begin{array}{c}\% \text { AGE 16-64 } \\
\text { WORKING } \\
2000\end{array}$ & $\begin{array}{c}\% \text { w/o HS } \\
\text { DIPLOMA } \\
2000\end{array}$ & $\begin{array}{c}\text { \% IN } \\
\text { POVERTY } \\
2004\end{array}$ \\
\hline $\begin{array}{c}\text { ROCKY } \\
\text { MOUNTAINS/ } \\
\text { AMENITY- } \\
\text { BOOM }\end{array}$ & $71 \%$ & $41 \%$ & $72 \%$ & $9 \%$ & $10 \%$ \\
\hline $\begin{array}{c}\text { NORTHEAST/ } \\
\text { AMENITY- } \\
\text { DECLINE }\end{array}$ & $3 \%$ & $-24 \%$ & $73 \%$ & $20 \%$ & $12 \%$ \\
\hline $\begin{array}{c}\text { MIDWEST/ } \\
\text { DECLINE }\end{array}$ & $-19 \%$ & $-50 \%$ & $78 \%$ & $14 \%$ & $11 \%$ \\
\hline \begin{tabular}{c} 
APPALACHIA \\
\hline DINELTA
\end{tabular} & $-12 \%$ & $-28 \%$ & $43 \%$ & $41 \%$ & $27 \%$ \\
\hline $\begin{array}{c}\text { B. } \\
\text { BLACK BELT }\end{array}$ & $-4 \%$ & $-21 \%$ & $54 \%$ & $32 \%$ & $2 \%$ \\
\hline
\end{tabular}




\section{Everywhere young people are advised to leave}
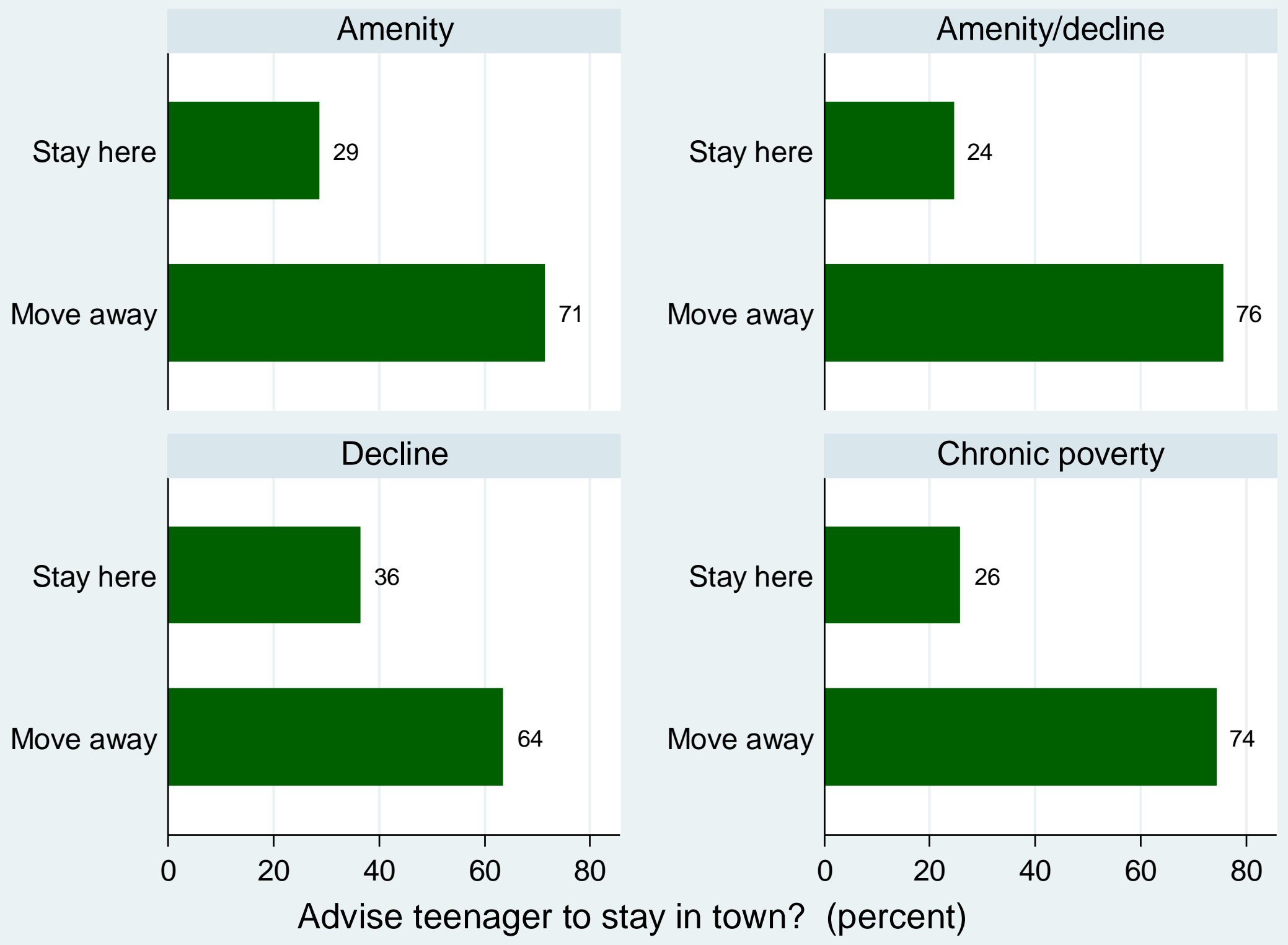


\section{Amenity areas have many newcomers, poor areas have few}
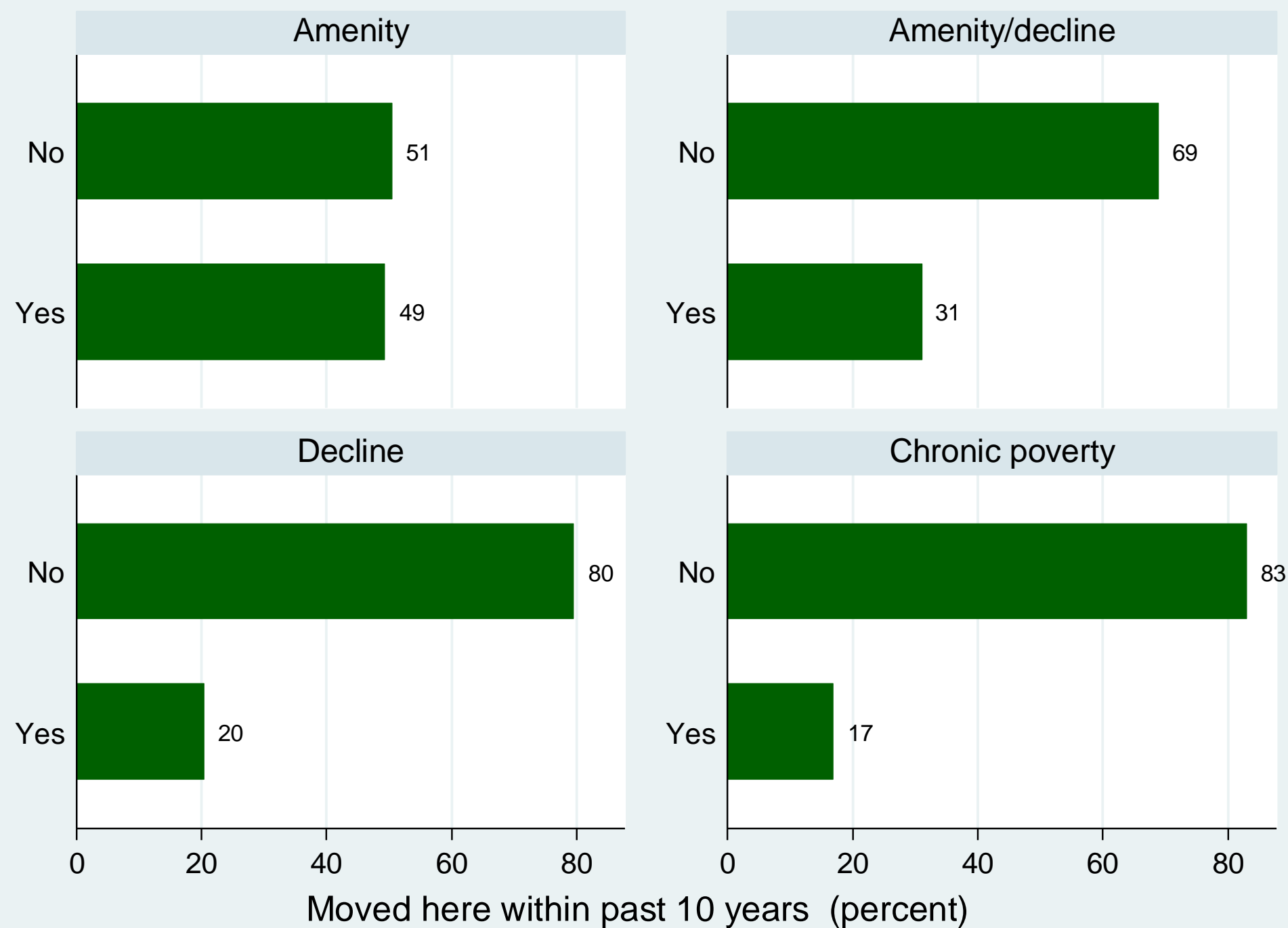


\section{Amenity rich areas are college grad rich}
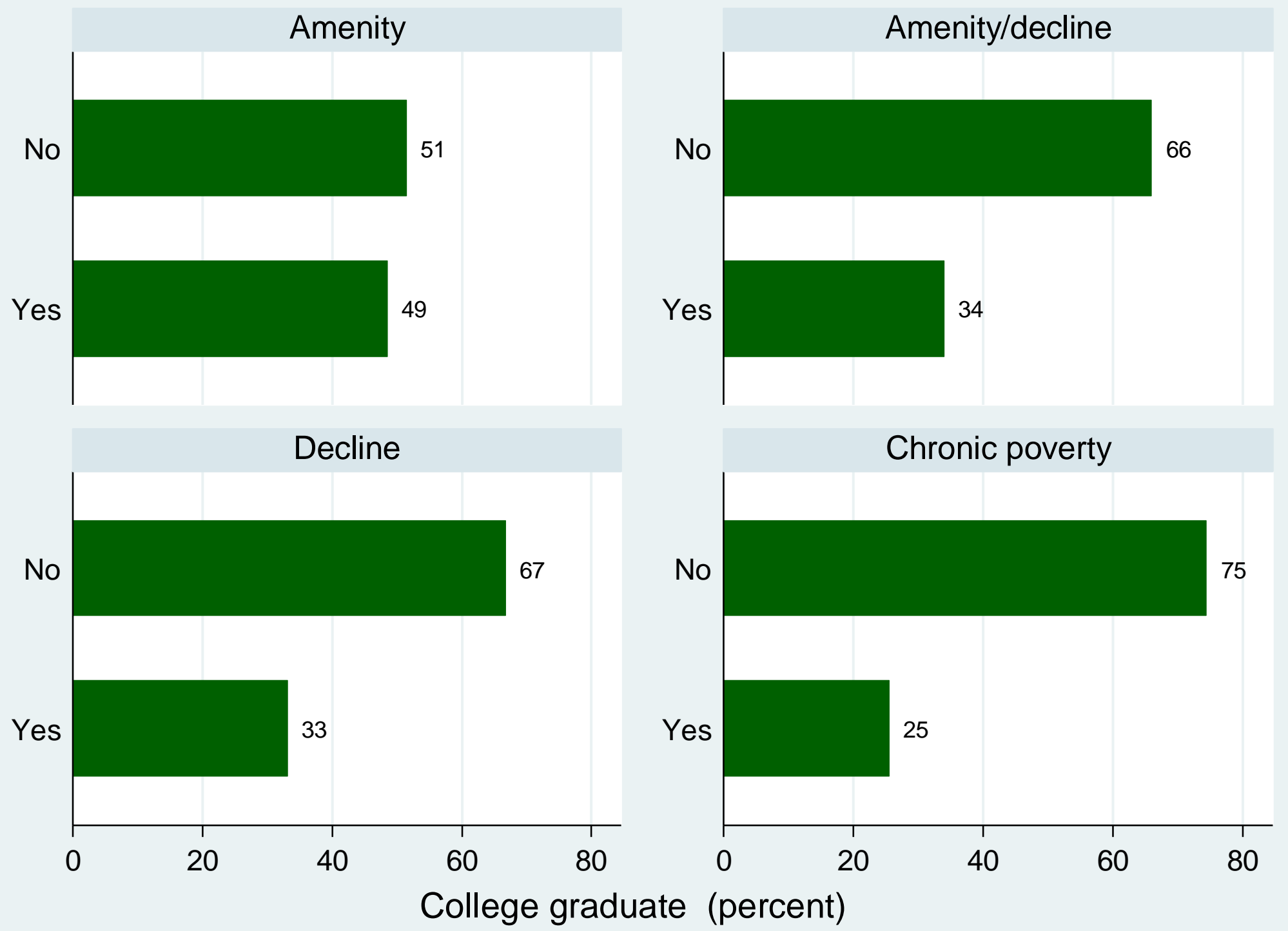


\section{That critical middle income group is relatively small in poor areas, larger in amenity areas}
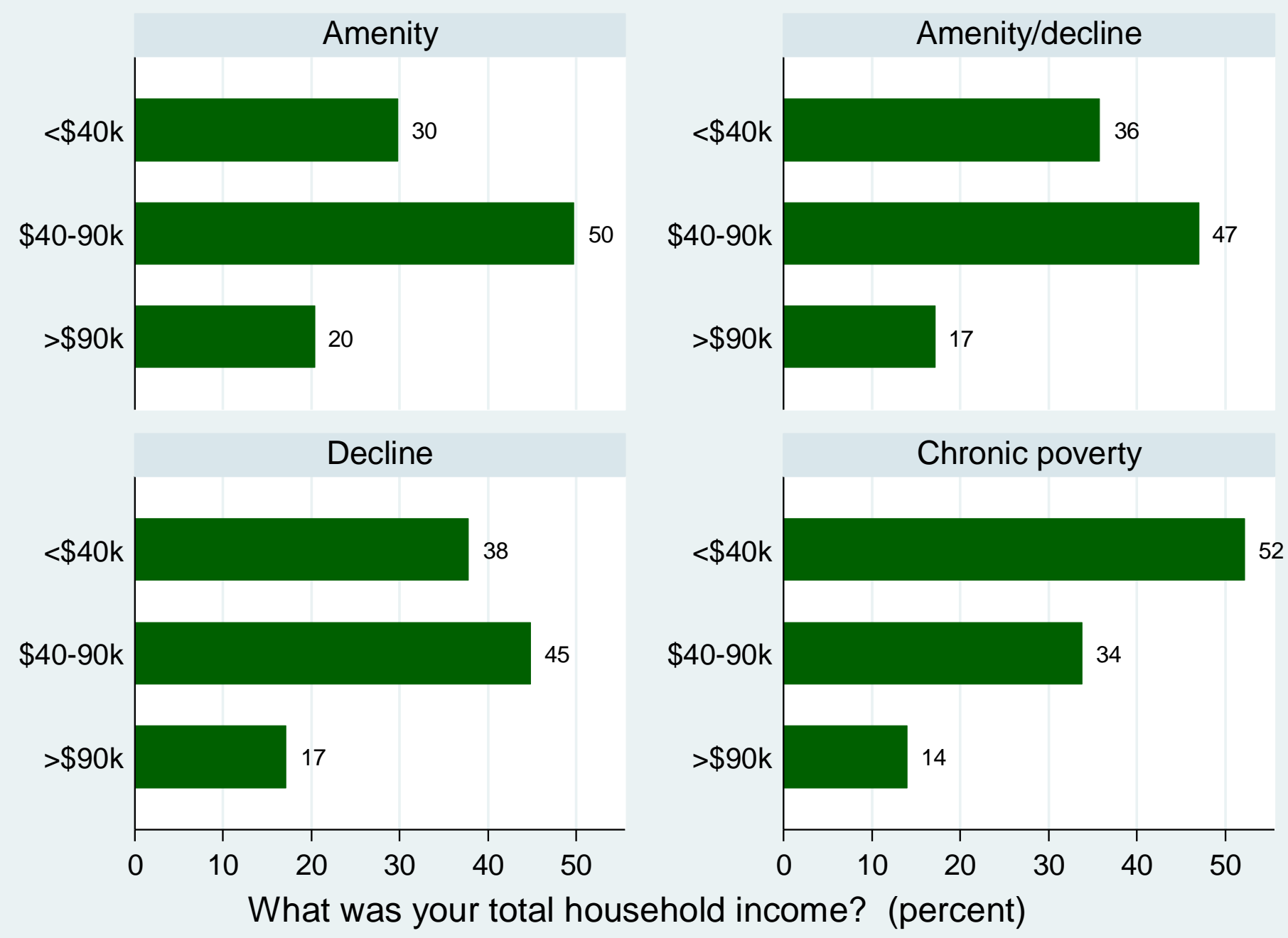


\section{Disability is high in poor areas - have a dog again}
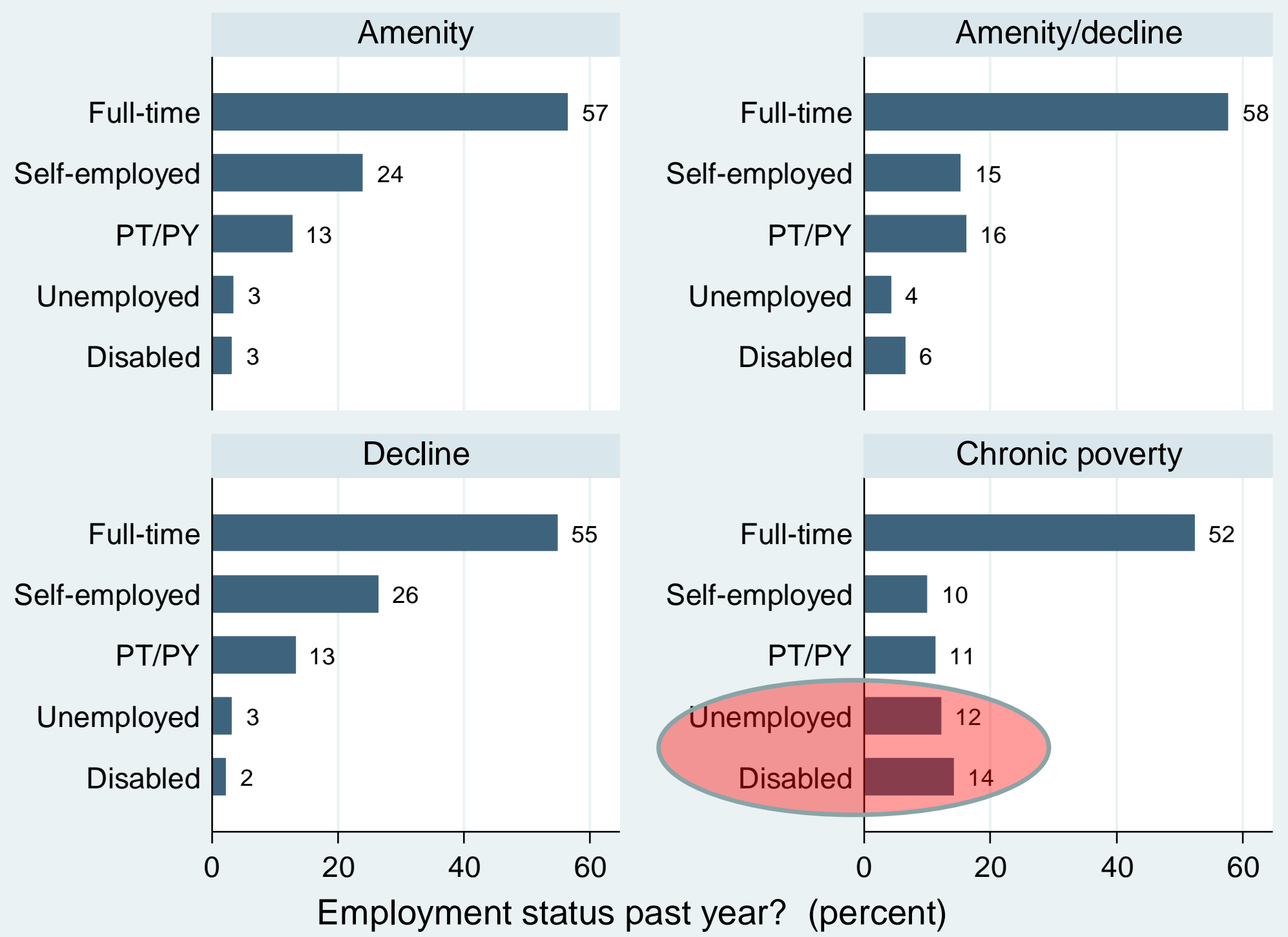


\section{Poor areas have many community needs, everywhere jobs are a priority}

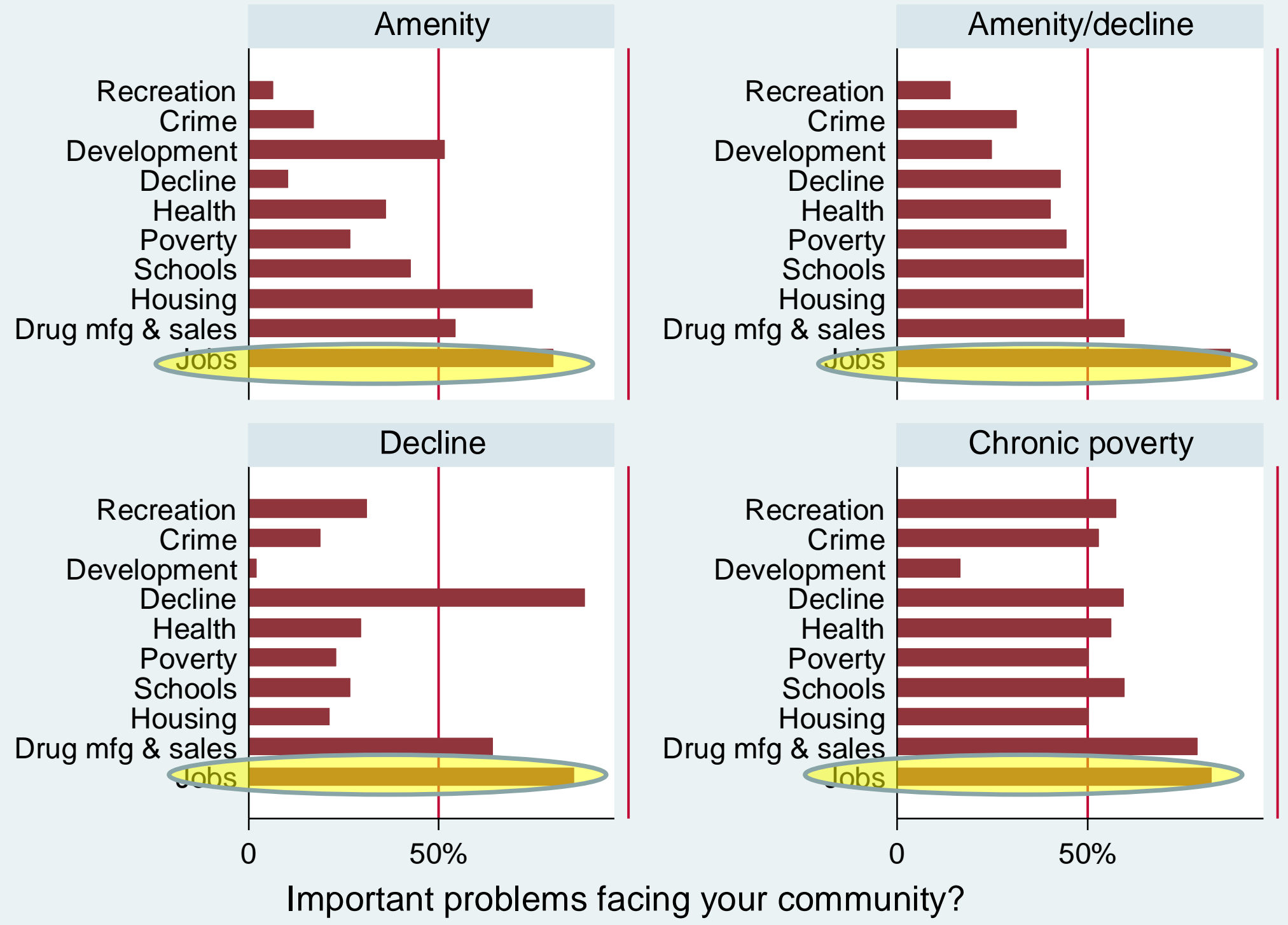




\section{Less Civic Engagement}
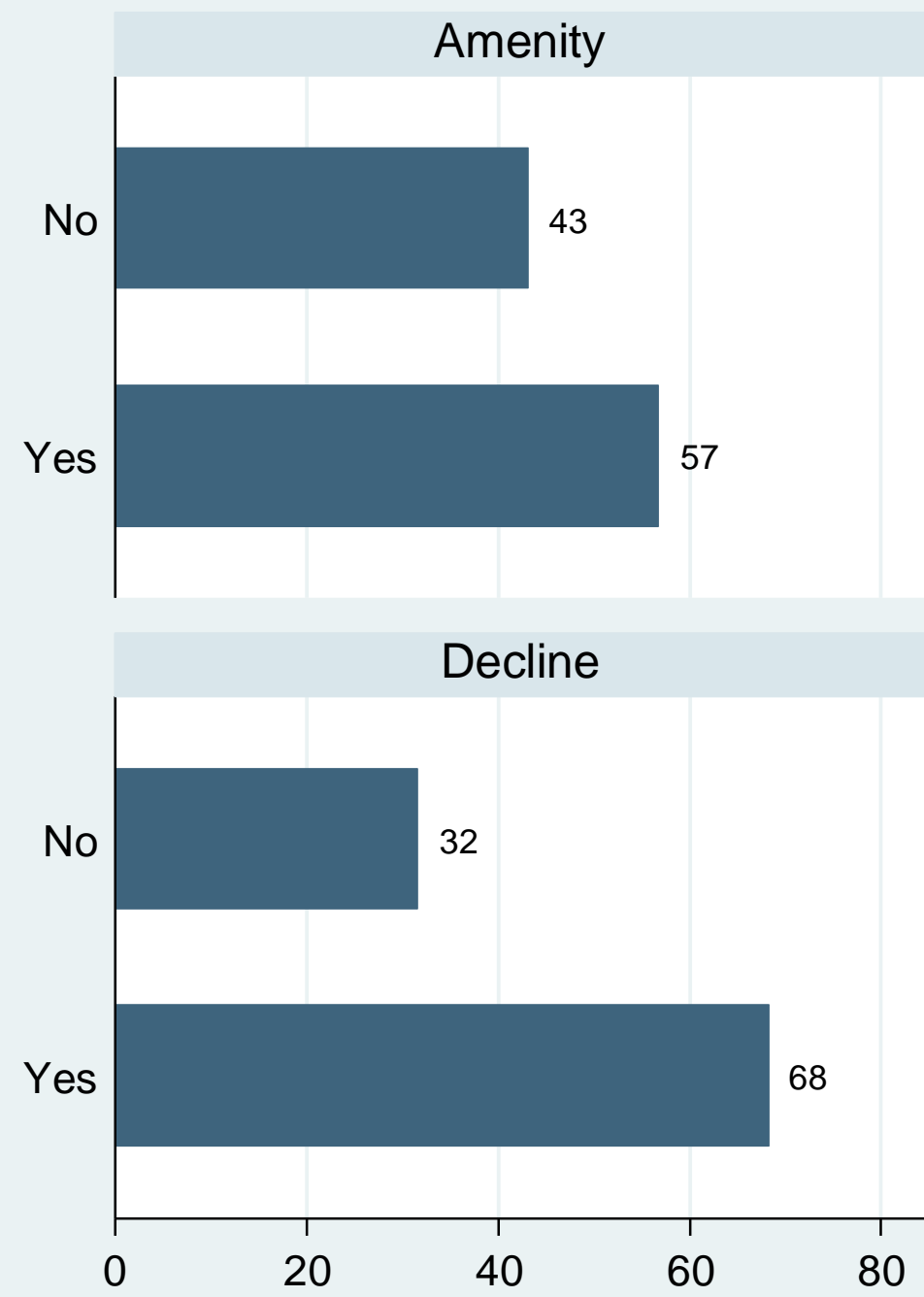
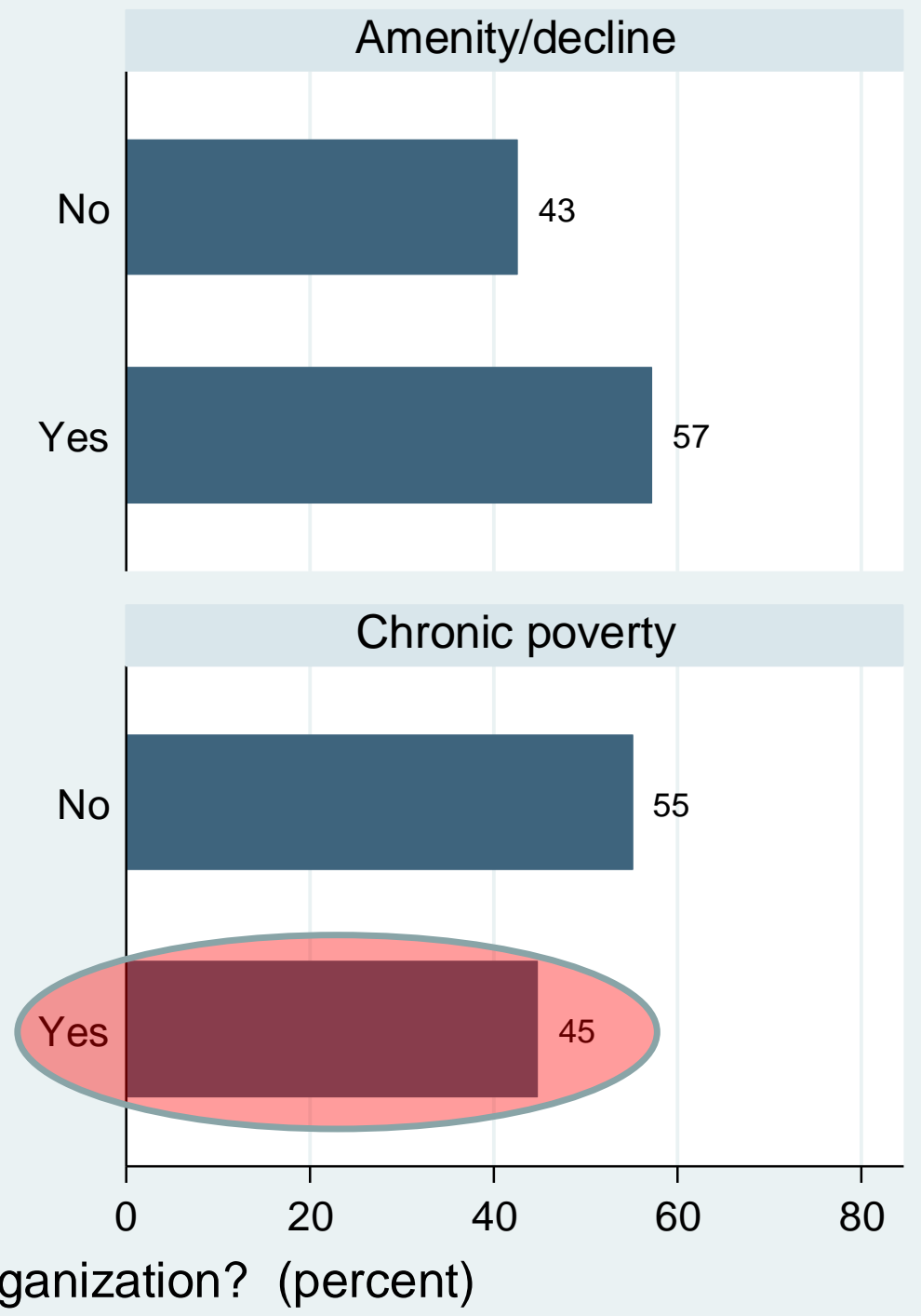


\section{And Less Trust}

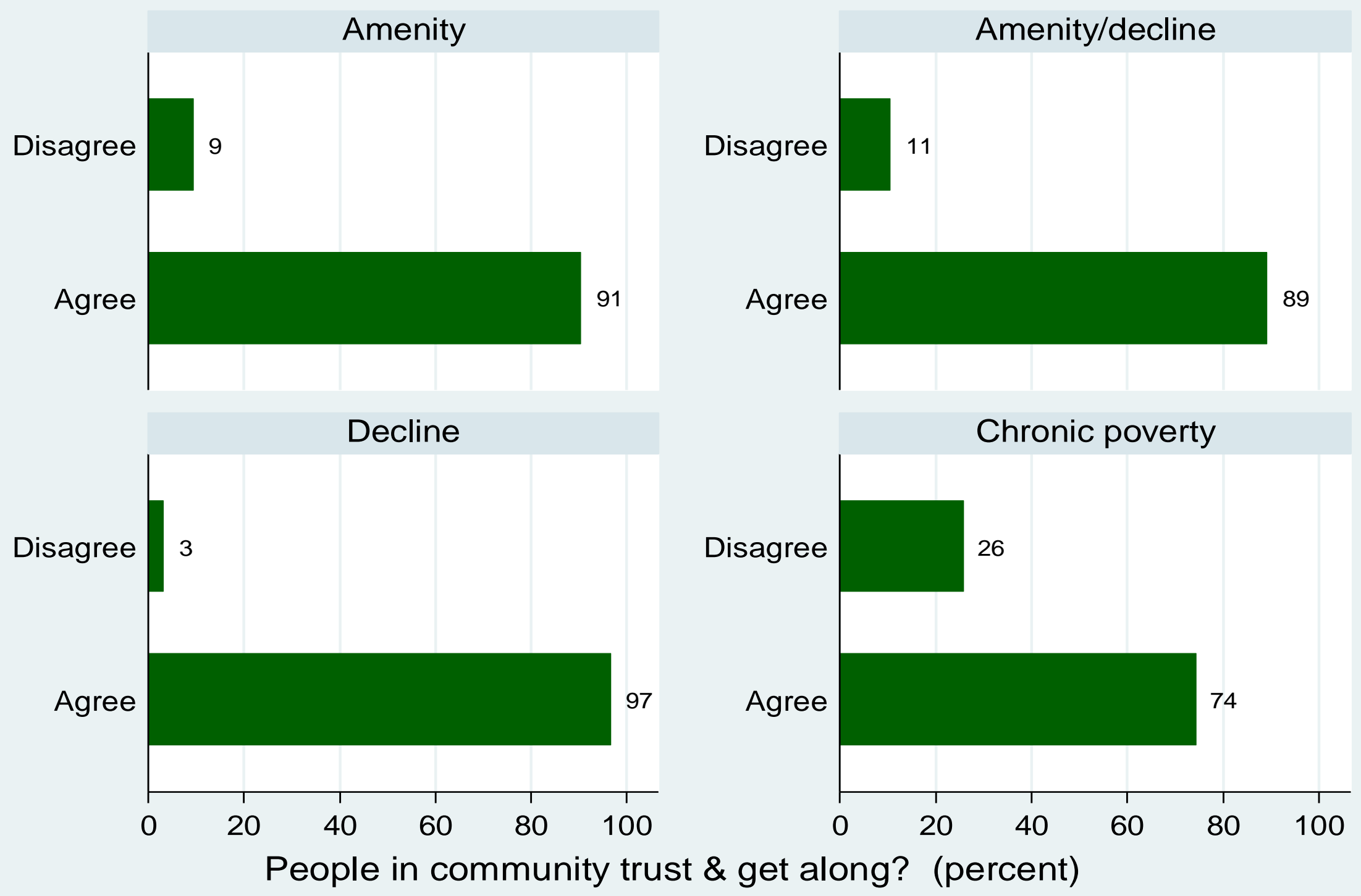




\section{Poverty as Exclusion}

"Poverty is the lack of adequate resources to participate in the "accepted ways" in society."

"Social exclusion" - being cut off from, left out of, the mainstream and participation in the wider society 


\section{William Julius Wilson's insights about poor areas in Chicago are still relevant}

Work disappeared, especially for low skill workers seeking stable blue collar jobs.

The black middle class left the ghetto, leaving neighborhoods

- without role models

- with little access to cultural learning about the mainstream, and

- disinvestment in community institutions. 


\section{Culture as a "tool kit of symbols, stories, rituals, and world-views."}

- Skills and habits, not preferences and wants

- What we know of the world, how it works, where we fit

- What people like us do 


\section{Civic Culture}

- To what extent do people trust each other?

- To what extent do people from all walks of life participate in community affairs and decisions?

- To what extent do people invest in the community - spend time and even money building things that benefit others outside their own family? 


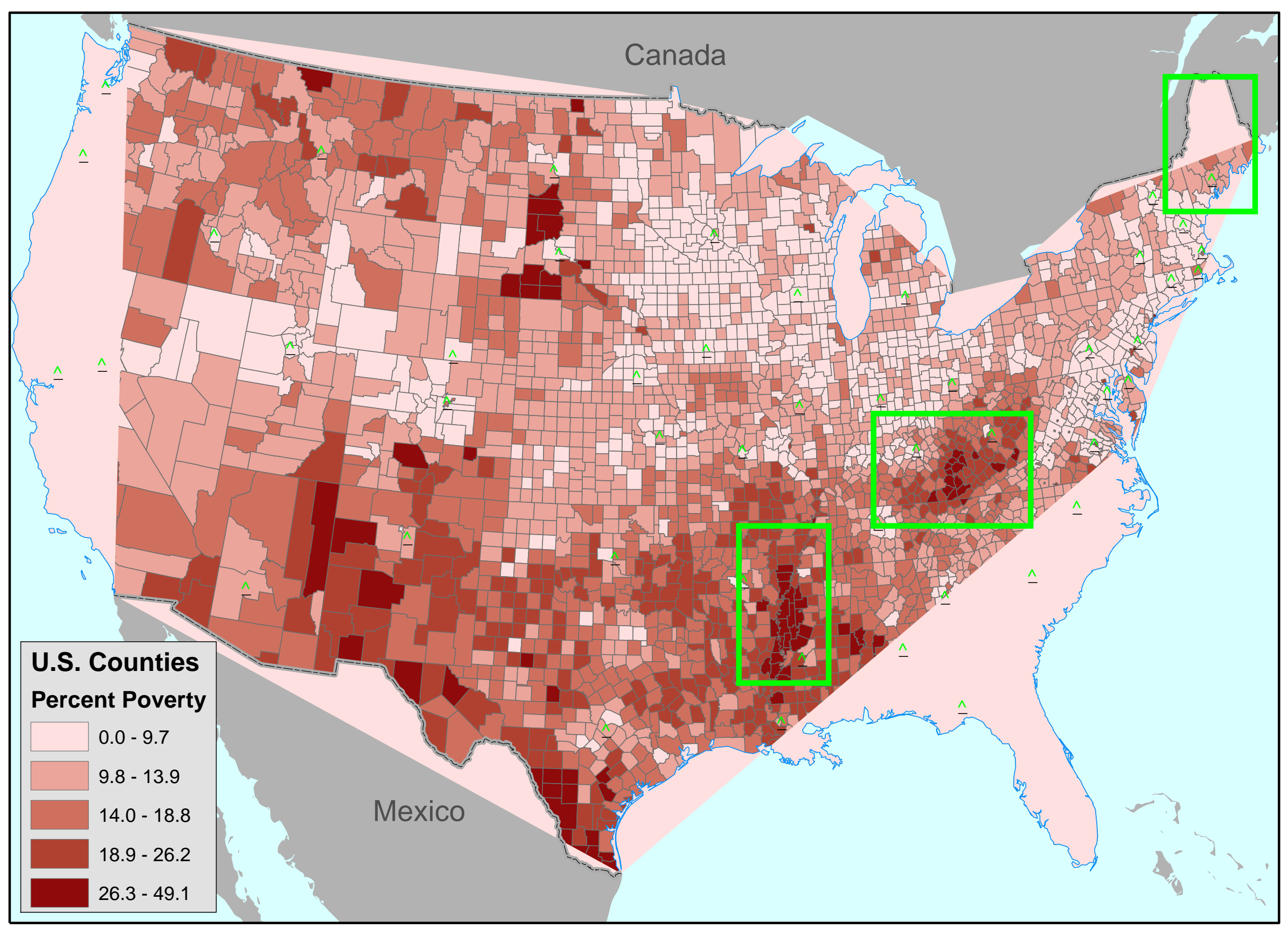

Source: U.S.Census http://www.census.gov/hhes/www/poverty/poverty.html Map created in ArcGIS 9 using ArcMap 


\section{Haves and Have-nots in Poor Rural Places}

- The poor are socially isolated, worlds apart from the haves.

- They do not develop the "cultural learning," skills and contacts that they need to participate in the mainstream.

- There is no middle class to demand high standards in public schools and hold public officials and employers accountable for honest fair practices. 


\section{Appalachia: family name matters}

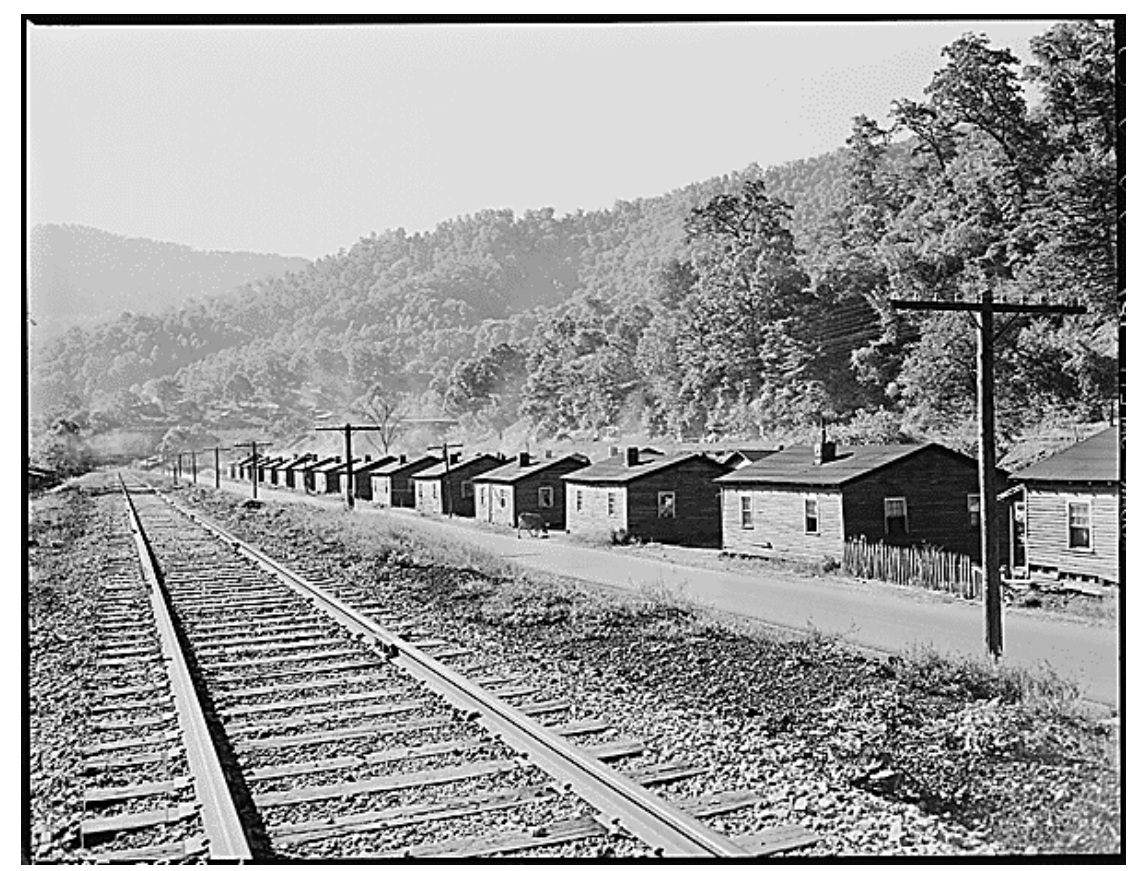

- "A lot of times you can hear somebody's last name and before you even meet, you've already got the idea that they're either a good person or they're sorry as can be."

- Those that have a family with a horrible name, when they come in, we know them, and they're not worth two cents. They're sorry as can be stealing, selling dope, bootlegging, picked up for driving drunk, in and out of bankruptcy court." 


\section{Family, not community, concerns}

"I see people very, very concerned about their own families, and their concern stops there. They're strongly family oriented here. And they would do anything for their family.

They have a great concern for their own family. I've talked to my congregation. This concern ought to go beyond family."

-- Minister in Appalachia 


\section{Delta: Blacks are the have-nots, and they are still vulnerable}

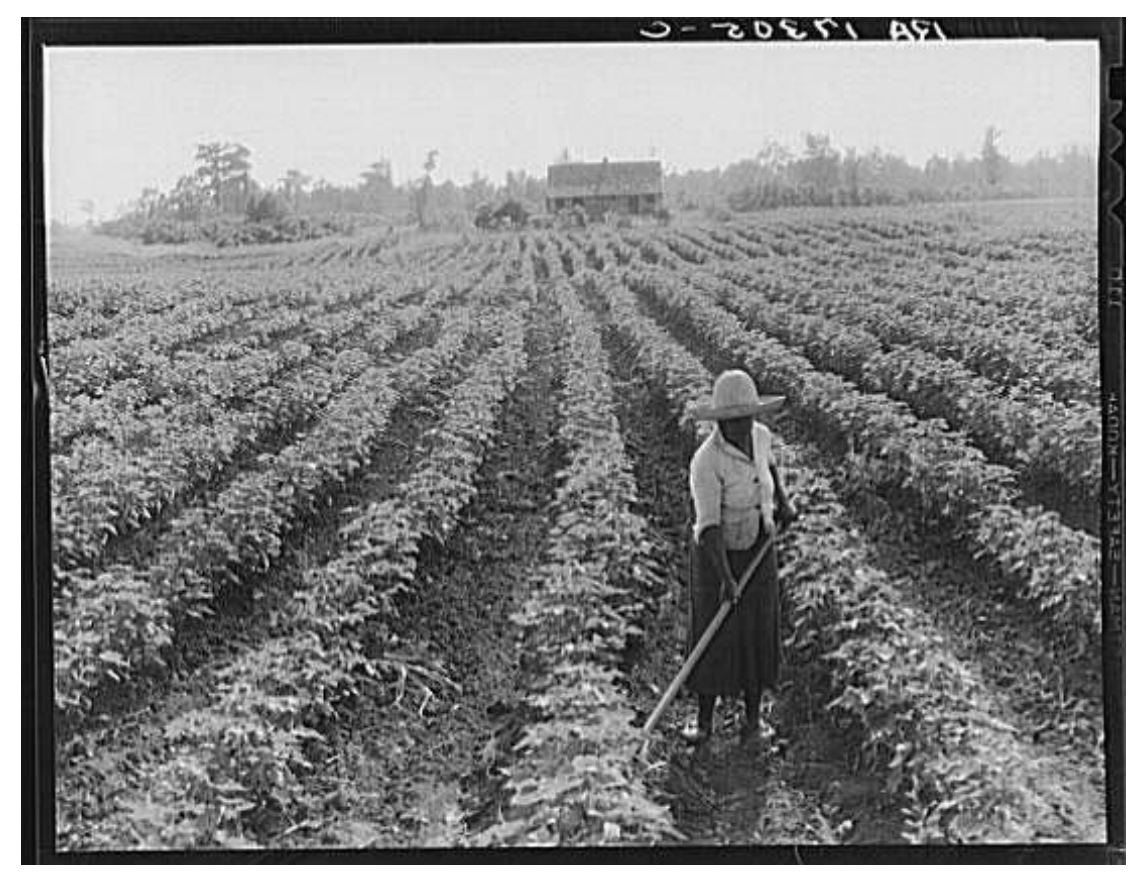

- "If one of the blacks was to piss Jimmy off--you know he drives for a farmer--he could make it hard on him if he said something to his boss. He could make it really hard on the boy, make him get fired.

- It's just over here the blacks don't have the opportunities that whites does. They're really disgraded."

--Truck driver's wife in the Delta 


\section{Change comes slowly}

"Blacks who have known only the plantation and a life in which they relied on the bossman will vote with him out of habit and deference...

Uneducated people need to go through someone, they need to get help from Toms that have been there for a long time and the whites have gained control of them."

-African-American leader in the Delta 
Places with a middle class have trust and invest in the common good, so the poor can build cultural tool kits that equip them for mobility

"We're a working community...

There's very little difference between people... That's one nice thing about the town, that there doesn't seem to be any class-level distinctions. We have a broad, working middle-class. Most of the people who live here feel that they're part of the community.

You know the people next door and you trust the people next door. We're a small, somewhat isolated community, and therefore, people tend to get along, are open with each other."

-- small business leader in northern New England mill town 


\section{Importance of Community}

- In rural communities, individuals and families' well being is intertwined with how the community is doing

- Not just job creation and economic development

- Also civic culture and the strength and resilience of community institutions dedicated to the common good. 


\section{Lessons from the Four Rurals: Policy Recommendations}

- Chronic Poverty

- Amenity-Boom

- Land/amenity protection

- Living wage

- Affordable housing

- High-speed internet

- Decline

- Financial incentives to reverse population loss

- Build on social capital

- High-speed internet
- Public education investment

- Resource stewardship and environmental restoration

- Healthcare, substance abuse counseling

- High-speed internet

- Amenity-Decline

- Infrastructure and economic development

- College-business partnerships

- High-speed internet 
Albert Hirschman talked about three choices:

$$
\text { Exit, Loyalty and Voice }
$$




\section{Education Education Education}

Education is key asset for escaping and staying out of poverty, as well as for voice. $\sim$ Colleges are key institutions for building voice and civic culture. 
